\title{
Entre o reflexo e a proposição. Dilemas sobre 0 encerramento dos fóruns deliberativos ${ }^{1}$
}

LUIEI BOBBIO"

\section{Resumo}

Como se pode encerrar uma deliberação? Qual o resultado concreto que um fórum deliberativo pode transmitir às instituições e ao público? A teoria deliberativa não é clara sobre isso, embora a prática tenda a oscilar entre diferentes soluções. Em princípio, a conclusão de uma deliberação deveria responder a dois critérios: fidelidade e univocidade. Porém, como esses critérios são contraditórios, tende-se a privilegiar um ou outro nas experiências concretas. Analisando seus dispositivos mais difundidos, o artigo considera quatro tipos de encerramento dois visam mais à fidelidade (as "conclusões reflexo") e dois visam à univocidade (as "conclusões proposição") - e avalia os pontos fortes e fracos de cada um.

Palavras-chave: Teoria deliberativa. Conclusão do processo deliberativo. Júris cidadãos. Participação social.

1 Este artigo se baseia em uma comunicação apresentada no colóquio "Le tournant délibératif: bilan, critiques, perspectives", Paris, EHESS, 16-17 junho de 2011. Tradução de Patrícia C. R. Reuillard (UFRGS).

* Luigi Bobbio, Università di Torino, Dipartimento di studi politici, via Giolitti 33, 10123 Torino, Itália. Tel. +390116704109, luigi.bobbio@unito.it 


\section{Between reflex and proposition. Dilemmas in closing deliberative forums}

\section{Abstract}

How can we end a deliberation? What is the concrete result that a deliberative forum may address to the institutions and the public? The deliberative theory is not clear on this issue, while the practice tends to switch between different solutions. In principle, the conclusion of a deliberation should meet two criteria: faithfulness and straightforwardness. Since these criteria are contradictory, practical experiences tend to favour one of them. Through the analysis of the most diffused practices, the paper considers four types of conclusions, two of them point mostly on fidelity (the "mirror conclusions") and two on straightforwardness (the "proposal conclusions"). The strengths and weaknesses of these four types of conclusion are then evaluated.

Keywords: Deliberative theory. Conclusion of deliberative process. Citizen's juries. Social participation.

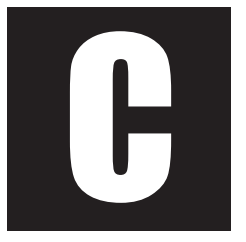

omo se pode encerrar uma deliberação? Qual o resultado concreto que um fórum deliberativo pode transmitir às instituições e ao público? O problema do encerramento da deliberação constitui - em minha opinião - um ponto fraco da teoria da deliberação e, sobretudo, da prática (minipúblicos, fóruns deliberativos, debates públicos, etc., Fung, 2003), pois a teoria dedica-se mais ao processo do que à sua conclusão. Ela presume que o próprio fato de argumentar em grupo, em condições de paridade, produz efeitos virtuosos independentemente das conclusões adotadas ao final da discussão: o processo deliberativo melhora as relações entre os participantes, favorece a aprendizagem, atenua os preconceitos, etc. No entanto, embora a deliberação não seja apenas uma discussão ou uma con- 
versa (Manin, 2005; Urfalino, 2005), mas uma confrontação argumentada e voltada à solução de um problema ou ao desfecho de uma controvérsia ou conflito, é importante ver se e como essas dificuldades são efetivamente resolvidas. Ou, então, o que resulta delas. Aliás, pode-se supor que a principal virtude da deliberação é produzir algo que não existia anteriormente: ou redefinindo (ampliando, modificando, esclarecendo) o problema inicial, ou encontrando soluções inéditas. Portanto, seu encerramento é importante e não pode ser negligenciado.

Nem sempre a teoria é precisa sobre esse assunto. Discutiu-se muito a "impossível" fórmula da "força do melhor argumento" de Habermas, questionou-se se a necessidade real do consenso, ou a admissibilidade do voto. Interrogou-se a possibilidade de substituir o consenso (frequentemente impossível ou não desejável) por saídas mais flexíveis e, ao mesmo tempo, mais realistas, como o metaconsenso (Niemeyer e Dryzek, 2007), isto é, um consenso mais sobre a natureza da questão do que sobre a solução, ou - em um espírito pragmático - a confluência em torno de um problema comum (Kadlec, 2008).

Esses arrazoados não se traduzem facilmente na prática. As experiências concretas necessitam chegar a uma conclusão, são obrigadas a produzir um resultado capaz de mostrar ao exterior o que a deliberação concluiu. Uma discussão sem desfecho corre o risco de permanecer muda e, portanto, de parecer inútil. Se cidadãos fazem o esforço de se reunirem, de se informarem, de refletirem juntos, eles devem mostrar os resultados disso.

Na prática dos fóruns deliberativos, encontraram-se soluções muito diferentes, até opostas, que revelam um certo constrangimento em relação a esse assunto. O problema é que o encerramento de uma deliberação deveria responder a dois critérios contraditórios: fidelidade e univocidade. De um lado, o encerramento deveria ser o mais fiel possível ao processo deli- 
berativo que o antecedeu, sem trair as vozes dos participantes. De outro, ele deveria ser o mais claro e preciso possível para comunicar ao exterior de maneira eficaz o conteúdo dos resultados. O primeiro critério visa o ponto de partida, a coerência com o debate; o segundo critério visa sua continuidade, o impacto da deliberação no público, nas instituições competentes e - pode-se acrescentar - no sistema deliberativo em sua complexidade (Mansbridge et al., 2011). Trata-se do problema da relação entre o nível micro e o nível macro (Hendricks, 2006; Goodin, 2008).

Os dois critérios são potencialmente contraditórios: uma conclusão fiel corre o risco de não ser suficientemente clara e de não responder de modo preciso à pergunta que todos fazem ao final de uma deliberação: "mas, resumindo, o que foi decidido?". Uma conclusão clara, ao contrário, corre o risco de não ser muito fiel, de suprimir nuances, dúvidas ou mesmo divergências, em nome da visibilidade. Razão do dilema: é preferível refletir o que aconteceu ou fazer uma síntese? É preferível um encerramento que se apresente como um reflexo ou um encerramento que assuma a forma de uma proposição ou de uma escolha? Nas experiências práticas, tende-se a oscilar entre os dois, conforme o objetivo almejado. Alguns dispositivos visam, sobretudo, ao "encerramento-reflexo"; outros, ao encerramento-proposição". Considerando as diferentes experiências deliberativas do mundo real, parece-me que se pode agrupar as formas principais de encerramento em quatro tipos: dois tendem ao modelo do reflexo e dois ao modelo da proposição.

\section{Mudança das opiniões}

O primeiro tipo de conclusão, que reflete o processo sem formular nenhuma proposição, é o adotado pelas sondagens deliberativas (Deliberative Pollings, Fishkin, 1995, 2009) e, às vezes, também por outros dispo- 
sitivos (por exemplo, júris de cidadãos). Nesses casos, o resultado final da deliberação consiste em uma comparação entre as opiniões expressas pelos participantes, sobre as mesmas questões, antes e depois do processo. A deliberação encerra-se mostrando se e como suas opiniões mudaram. Sua conclusão é a medida dessa mudança. As sondagens deliberativas não formulam nenhuma escolha, não tomam nenhuma decisão, não visam a um consenso nem à resolução de conflitos. As pessoas recebem informações, fazem perguntas aos especialistas, discutem em pequenos grupos e, ao final, preenchem um questionário com os mesmos itens que já haviam respondido quando recrutadas.

\section{A sondagem deliberativa}

A sondagem deliberativa (Deliberative Polling) foi proposta por James Fishkin (1995, 2009), com o objetivo de examinar como cidadãos comuns, sorteados aleatoriamente, mudam suas opiniões depois de receber informações sobre um problema de caráter público e de discuti-lo com especialistas. As sondagens deliberativas envolvem entre 200 e 600 pessoas e são geralmente realizadas ao longo de um fim de semana. A informação é transmitida aos participantes através de material informativo especial, elaborado em conjunto pelos principais interessados; a discussão é realizada em pequenos grupos em que os participantes, reunidos em sessão plenária, fazem perguntas aos especialistas e políticos. Um mesmo questionário é aplicado aos participantes antes e depois do evento, para verificar eventuais mudanças de opinião.

Na Itália, uma sondagem deliberativa foi realizada em Turim, em 2007, sobre os direitos de voto dos imigrantes e sobre um projeto de infraestrutura (uma nova linha ferroviária Lyon-Turim) que era alvo de intensa polêmica na região em que seria construída (Isernia et al., 2008). 
Essa abordagem baseia-se na ideia - fundamental na teoria da democracia deliberativa - de que as preferências não são definitivas, mas que evoluem e se modificam quando expostas a uma troca discursiva. A prática das sondagens deliberativas teve o grande mérito de demonstrar, após inúmeras experimentações, que, de fato, há importantes mudanças de opinião e, principalmente, que essas mudanças orientam-se para atitudes menos egoístas e mais solidárias. Por essa razão, criticam-se as sondagens tradicionais, que só detectam opiniões brutas.

A meu ver, o problema principal desse procedimento é que o resultado da deliberação é verificado somente em nível individual. Vê-se como cada participante se transforma, mas não se vê se há consequências coletivas. Os participantes não são encorajados a oferecer novas soluções ou novas visões do problema. Além disso, como o questionário é preparado de antemão, ele não pode levar em conta os novos temas ou as novas abordagens que surgem no debate. Refletem-se as posições dos participantes sobre as questões que os organizadores já haviam previsto desde o início, mas não se podem registrar as diferenças ocorridas ao longo do processo. Tudo permanece no nível individual. Os resultados provenientes dos questionários são fiéis, mas refletem apenas a transformação das preferências individuais em eixos determinados de antemão.

A eficácia dos questionários é variável. Na maioria dos casos, os itens são muito numerosos e as respostas revelam várias tendências, que devem ser interpretadas. Os resultados podem ser mais claros quando existe uma problemática principal (por exemplo, no caso da sondagem deliberativa sobre a adoção do euro na Dinamarca) (Andersen e Hanse, 2007). 


\section{Representação dos discursos}

Uma outra maneira, completamente diferente, de oferecer um reflexo ao desenrolar da discussão é apresentar, ao final da deliberação, a pluralidade dos temas, demandas, argumentos e posições que circularam durante o processo. O documento conclusivo é um catálogo, mais ou menos argumentado, de tudo que resultou da deliberação. Tampouco nesse caso a deliberação chega a uma proposição, mas não são as opiniões dos indivíduos que são detectadas (e contadas), e sim os argumentos apresentados, independentemente de terem sido defendidos por um grande número de participantes, por grupos minúsculos ou até mesmo por uma única pessoa. Nesse caso, é a natureza ou a qualidade do argumento que conta, não a amplitude da adesão. Renuncia-se a qualquer forma de cumulação quantitativa (presente, ao contrário, no procedimento anterior), limitando-se a representar - qualitativamente - a totalidade dos argumentos sem posicionar-se sobre nenhum deles. Esse procedimento corresponde a um outro princípio evocado pelos teóricos da deliberação: um fórum deliberativo não deve ser representativo dos indivíduos, mas dos discursos - de todos os discursos - existentes na sociedade sobre a questão submetida à deliberação (Drysek e Niemeyer, 2008). Nessas experiências, o objetivo da deliberação é encorajar a expressão e o confronto de todos os discursos; portanto, seu resultado consiste em um levantamento dos discursos e das discussões feitas. Diferentemente do procedimento anterior, neste o levantamento final pode registrar os novos temas surgidos no debate e provocar surpresas.

Várias experiências deliberativas terminam com encerramentos desse tipo. É o caso das "reuniões em espaço aberto" (Open Space Technology), onde os participantes são convidados a propor temas e a discutilos com os interessados. O objetivo é explorar uma ampla variedade de temas e de abordagens e incitar à criatividade. Nessas reuniões, não se 
Sociologias, Porto Alegre, ano 14, no 30, mai./ago. 2012, p. 46-69

busca decidir, mas, ao contrário, explorar uma vasta gama de possibilidades. O relatório final é apenas a apresentação dos temas escolhidos e das discussões feitas nos grupos.

\section{Open Space Technology}

Trata-se de uma ferramenta, proposta por Harrison Owen (1997), adequada a abranger um público entre 100 e 300 pessoas em eventos cujo objetivo é levantar livremente temas, problemas e soluções. Não há oradores convidados para falar nem programa predefinido. A reunião é organizada a partir do princípio de que são os participantes, reunidos em um grande círculo e informados sobre algumas regras de trabalho, que elaborarão o programa do encontro. Os participantes que desejarem podem propor temas para discussão e reunirem-se para discuti-las com quem quiserem. Ao final do dia, é apresentado um relatório breve com os temas de debate e um resumo das discussões nos grupos. O método é particularmente adequado para explorar um situação crítica através de um processo participativo.

Nos últimos anos, foram realizadas dezenas de experiências deste tipo na Itália (Garramone e Aicardi, 2009).

Um encerramento semelhante ocorre em um contexto bem diferente - os conflitos sobre as infraestruturas -, no caso dos debates públicos administrados pela Comissão Nacional do Debate Público, na França (Revel et al., 2007). Nesse caso, o que se busca decidir é a oportunidade e o conteúdo de um projeto. Todavia, a definição da decisão não é deixada ao debate, mas ao gestor do projeto após a conclusão. O debate tem um outro objetivo: levantar os argumentos, isto é, permitir a todos os cidadãos envolvidos que expressem seus pontos de vista plurais. O relatório da comissão particular do debate público consiste, portanto, em uma apresentação argumentada do estado da questão. 


\section{O debate público francês}

Após os intensos protestos da população local contra o traçado da linha férrea de trens de alta velocidade entre Lyon e Marselha, no início dos anos 1990, o governo francês decidiu que os projetos de grandes obras públicas deveriam ser submetidos previamente a um debate público entre todas as pessoas interessadas. Com a Lei Barnier, de 1995, parcialmente alterada em 2002, foi instituída uma autoridade independente, denominada Comissão Nacional do Debate Público (CNDP), com a competência de estabelecer um debate público sobre todos os grandes projetos de infraestrutura que atendessem a determinados requisitos. O debate tem a duração de quatro meses e abrange não só as características do projeto, mas também a oportunidade de realização da obra. É precedido de uma extensa campanha informativa voltada à população envolvida, da qual participam todas as associações e grupos que o desejarem. Após o debate público, o presidente da Comissão elabora um relatório do qual constam os argumentos a favor e contra coletados ao longo dos quatro meses. No prazo de três meses a partir da publicação do relatório, o proponente da obra deve informar de sua intenção de seguir com o projeto, alterá-lo ou retirá-lo (Fourniau 2001, Revel et al., 2007).

O mesmo mecanismo foi utilizado na Itália no caso do distrito de Castelfalfi e da autoestrada urbana de Gênova.

\section{O debate público sobre o vilarejo de Caltelfalfi}

Castelfalfi é um vilarejo medieval, no município de Montaione, na Toscana, quase totalmente abandonado. Foi comprado por uma empresa alemã, que decidiu transformá-lo em um resort turístico, com a restauração dos antigos prédios e a construção de novos. O município decidiu abrir um debate público, administrado pela Garantia Geral da Comunicação, que durou quatro meses (de setembro a dezembro de 2007). O relatório final da Garantia deu ao município a possibilidade de negociar com a empresa proprietária uma diminuição das novas construções (Floridia, 2008).

http://www.dp-castelfalfi.it/home.page 


\section{O debate público sobre o contorno rodoviário de Gênova}

O município de Gênova decidiu, no final de 2008, com o consentimento do proponente privado da obra (a Società autostrade), submeter a um debate público o projeto de um contorno rodoviário de $20 \mathrm{~km}$ a oeste da cidade, já rejeitado em 1990 por oposição dos moradores: o traçado passava em meio urbano e várias casas teriam sido demolidas. Dessa vez, decidiu-se apresentar ao público cinco alternativas diferentes de traçado. O debate, administrado por uma comissão independente, formada por especialistas estrangeiros ao meio genovês, seguiu de perto o modelo francês. Desenrolou-se em três meses em um contexto muito turbulento devido às contestações dos comitês dos moradores. Após a conclusão do debate, o proponente escolheu uma das cinco alternativas, com várias mudanças, a fim de minimizar o impacto da autoestrada sobre as habitações. Essa escolha foi aceita pelas coletividades locais e, em 2011, o proponente concluiu o projeto (Bobbio 2010; Pomatto 2011).

http://urbancenter.comune.genova.it/spip.php?rubrique7068

\section{A lei toscana sobre participação}

Em 2007, após um complexo processo participativo que durou mais de um ano, o Conselho Regional da Toscana aprovou a primeira lei sobre a participação promulgada na Itália. A lei prevê o estabelecimento de uma autoridade independente monocrática, denominada "Autoridade regional para a garantia e promoção da participação", que é designada pelo Conselho Regional após este ouvir os candidatos, e que tem como principais atribuições:

- gerenciar o debate público prévio sobre projetos de grandes obras (conforme o modelo francês);

- selecionar os projetos de participação propostos pelas autoridades locais e pela sociedade civil com base em critérios estabelecidos por lei. Os projetos selecionados recebem apoio financeiro da região, bem como apoio técnico na forma de consultoria. 
A lei tem prazo de vigência: expira automaticamente ao cabo de 5 anos. Sua eventual renovação deve ser precedida de uma discussão aprofundada para avaliação de sua implementação nos cinco anos anteriores (Floridia, 2007). Nos primeiros três anos de execução, nenhum debate público sobre grandes obras foi realizado, mas a autoridade financiou 71 projetos participativos. A maioria deles foi proposta pelas autoridades locais. Apenas 10\% foram apresentados por associações ou por cidadãos (Irpet, 2011).

www.consiglio.regione.toscana.it/partecipazione/

O "catálogo dos discursos" que encerra esses tipos de fóruns pode ser percebido como inoperante. Nenhuma proposição é oferecida, nenhuma escolha é considerada. A decisão é remetida a outras instituições em um momento futuro. Mas ele tem uma vantagem. O relatório pode, facilmente, ser bastante fiel, pois seu conteúdo não prejulga diretamente a escolha final; portanto, não há um forte interesse na manipulação. Aliás, ninguém é impelido a um acordo ou a uma solução consensual; consequentemente, os participantes são livres para apresentar suas razões, sem nenhuma obrigação. Mesmo os opositores mais radicais podem aceitar participar do jogo sem o temor de caírem em armadilhas ou de serem cooptados (com exceções, como o caso do debate sobre as nanotecnologias na França; Laurent, 2010).

\section{Recomendações}

Um tipo de conclusão que se inclina mais para a proposição é a recomendação. Esse encerramento é muito comum, por exemplo, nos júris de cidadãos e nas consensus conferences (conferências de cidadãos). Nesses casos, um pequeno número de participantes (frequentemente 
sorteados) não se limita apenas a se informar, discutir e questionar os especialistas, mas consegue, ao final do processo (após um ou vários dias), emitir um parecer, que é enviado aos gestores e à opinião pública. Uma síntese é produzida pelos próprios participantes. As recomendações são documentos, em geral bem breves, que propõem linhas de ação sobre as questões submetidas ao júri, escolhem alternativas, sugerem a consideração de certos interesses ou de certas ideias. Para evitar uma pressão excessiva para um consenso e o conformismo, normalmente se admite que o documento final possa registrar opiniões divergentes.

Nesse caso, a deliberação culmina em uma ou várias escolhas. Parece, portanto, uma conclusão mais firme do que as anteriores, porque não se limita apenas a representar o estado da arte, mas expressa uma vontade precisa. No entanto, pode apresentar problemas de fidelidade. As recomendações são normalmente redigidas por facilitadores externos e, mesmo que o façam sob controle direto dos participantes (que, às vezes, acompanham a elaboração do parecer em um telão), não se pode excluir que os animadores possam influenciar seu conteúdo (mesmo sem pensar na manipulação voluntária que, de resto, é perfeitamente possível). Outros problemas provêm dos fenômenos de group thinking, conformismo, polarização (Sunstein, 2002; Setälä, 2010), particularmente prováveis quando o debate se desenrola entre cidadãos comuns, com posições originais pouco definidas e sem muita reflexão (Bobbio, 2010).

Porém, também a eficácia do parecer para o exterior pode ser questionada. Diferentemente dos júris no processo penal, o encerramento desses júris não consiste em um mero "culpado ou inocente". Com frequência, as recomendações contêm vários pareceres que não indicam uma clara linha de ação e podem ser interpretados de diferentes modos ou até mesmo serem instrumentalizados. Houve casos em que os legisladores apreciaram publicamente os resultados de um júri, enquanto escondiam 
aspectos pouco confortáveis para eles (Bobbio e Ravazzi, 2006). Existe também o risco de que os pareceres dos júris sejam racionais demais: proposições indefinidas, que diluem a diversidade das perspectivas e, portanto, não auxiliam a discussão coletiva sobre questões controversas.

\section{Os júris de cidadãos}

Os júris de cidadãos (citizen's juries), propostos por Ned Crosby nos anos 70 (Smith e Wales, 2000; Crosby e Nethercut, 2005), foram inspirados no funcionamento dos júris populares do direito processual norte-americano. Um pequeno número de pessoas (15 a 25), escoIhidas por sorteio, reúnem-se, ao longo de alguns dias (de 2 a 5), para discutir um tema controverso, ouvir as opiniões de especialistas e questioná-los e, ao final, deliberar para chegar a um consenso sobre o tema, o qual é transmitido aos gestores políticos na forma de recomendações. Os cidadãos são selecionados de modo a compor um grupo representativo de toda a população em termos sociodemográficos.

Na Itália, após as primeiras experiências (Bobbio e Ravazzi, 2006; Bobbio e Giannetti, 2007; Carson, 2006), foram realizados diversos júris de cidadãos no âmbito de implementação da lei de participação da região da Toscana (ver quadro).

\section{As consensus conferences}

É cada vez mais comum a ocorrência de temas tecnocientíficos socialmente controversos, até mesmo entre os próprios cientistas (vejase, por exemplo, os efeitos dos transgênicos, as ondas eletromagnéticas, a destinação do lixo radioativo, etc.). Para fazer frente a esses problemas, no final dos anos 1980, o parlamento dinamarquês decidiu promover "reuniões de consenso" (consensus conferences), formadas por 15 a 20 pessoas, escolhidas aleatoriamente, as quais, depois de dialogar com especialistas, podiam manifestar seu próprio ponto de vista ao parlamento (Joss 1998, Hendriks, 2005). A experiência foi replicada em outros países como, por exemplo, a França (Boy et al., 2000). 


\section{Voto sobre alternativas}

A forma da recomendação, apesar de seus defeitos, parece fortemente de acordo com a teoria da deliberação: os participantes chegam a uma posição comum (unânime ou quase) que não resulta de uma negociação, mas da confluência para uma visão compartilhada. A recomendação é a forma mais apropriada para mostrar concretamente que os participantes foram convencidos pela "força do melhor argumento".

Todavia, em alguns casos, prefere-se concluir o fórum deliberativo com uma votação sobre as alternativas possíveis. Apelar para o voto é, em princípio, algo mal visto pelos deliberativistas, devido a seu caráter agregativo, mas a maioria deles admite que uma votação suceda à discussão porque a unanimidade total é improvável (e, talvez, também perigosa). Além disso, o fato de contar as preferências dos participantes sobre as alternativas dadas tem a vantagem de estabelecer o resultado de modo claro e incontestável.

De fato, a virtude principal do voto é a univocidade: após o voto, todos sabem exatamente o que os participantes escolheram; também por isso o apelo ao voto é bastante frequente nos dispositivos deliberativos. Vota-se para classificar alternativas, por exemplo, nos orçamentos participativos; ou vota-se para escolher uma alternativa. No caso da assembleia dos cidadãos da Columbia Britânica, no Canadá, sobre o sistema eleitoral, os participantes votaram duas vezes: para decidir sobre manter ou mudar o sistema existente e, em seguida, para escolher entre duas proposições alternativas. A sondagem deliberativa ocorrida em 2006, em Maroussi, na periferia de Atenas, para escolher o candidato a prefeito do partido socialista se concluiu (diferentemente das outras sondagens deliberativas) com um voto que designou o candidato preferido pelos participantes (que foi aceito pelo partido). Também nas 21st Century Town Meetings (Assembléias Municipais do Século XXI), promovidas pela organização America Speaks (Lukensmeyer 
et al., 2005), frequentemente se vota. Pede-se aos participantes (bastante numerosos) que escolham entre as alternativas dadas, e eles podem fazê-lo rapidamente, graças à possibilidade do voto eletrônico, cujos resultados podem ser imediatamente visualizados em um telão.

\section{1st Century Town Meeting}

É um instrumento criado pela organização America Speaks (Lukensmeyer et al., 2005), que possibilita desenvolver uma discussão e tomada de decisão envolvendo um grande grupo de pessoas (algumas centenas ou milhares). Os participantes se reúnem em um só lugar e em pequenos grupos (10-12 pessoas), assistidos por um facilitador. Cada grupo tem à sua disposição um computador conectado em rede que transmite o conteúdo de sua discussão a uma instância central, que o revisa e reapresenta à plenária. É possível conhecer em tempo real as opiniões dos participantes através do instrumento de televoto. Os participantes podem ser selecionados com base em sorteio, podem ser convidados ou apresentar-se voluntariamente.

$\mathrm{Na}$ Itália, esse mecanismo tem sido utilizado com frequência (Garramone e Aicardi, 2011). O caso italiano aqui mencionado consistiu em um debate sobre a questão dos testamentos vitais (living will), que havia suscitado intensa polêmica entre católicos e secularistas no Parlamento. O debate foi realizado simultaneamente em Turim e em Florença, em 25 abril de 2009, entre cerca de 300 pessoas voluntárias (na sua maioria pertencentes a associações), utilizando-se o método do 21st Century Town Meeting (Ravazzi, 2011). O relatório final está disponível em: www.comune.torino.it/ biennaledemocrazia / testamentobiologico / pdf / instantreport.pdf

É a fidelidade que pode causar problemas, se as alternativas sobre as quais se vota não se originam na deliberação (mas são propostas pelo exterior) e se os participantes não tiveram a possibilidade de refletir sobre elas. No caso da Colúmbia Britânica, a fidelidade não está em questão, pois as alternativas eram provenientes de um debate que durou vários meses (Warren e Pearse, 2008), mas, em outros casos, o problema pode ocorrer. 
Nas 21th Century Town Meetings, por exemplo, as alternativas são apresentadas aos participantes pelos organizadores, que não podem levar em conta a discussão feita por centenas e mesmo milhares de participantes, divididos em pequenos grupos. Durante experiências desse tipo feitas na Itália, descobriu-se com frequência que os participantes tinham dificuldade para votar sobre alternativas que não correspondiam perfeitamente ao que estavam discutindo no grupo. Em um caso - o debate sobre a eutanásia organizado em forma de Town Meeting em Florença, em 2009 (ver quadro) -, os organizadores foram obrigados a mudar o modelo de conclusão durante o próprio processo. Ao invés de terminar com uma série de votações, eles preferiram, devido a protestos dos participantes, suspender toda votação e encerrar o debate com um documento que relatava o conteúdo das discussões, dentro do modelo da "representação dos discursos".

Maja Setälä et al. (2010) tentaram ver se a votação afeta a qualidade da deliberação, confiando a grupos no mesmo fórum deliberativo (sobre a instalação de uma nova central nuclear na Finlândia) duas tarefas diferentes: alguns deviam terminar com um voto, outros com uma recomendação compartilhada. Eles constataram que o segundo grupo conseguiu desenvolver uma discussão mais aprofundada e obtiveram mais informações, mas os que tinham de votar não receberam pressões mais fortes para se posicionar (contudo, deve-se acrescentar, a questão em jogo não tinha muitas consequências: tratava-se de uma mera experimentação que não pretendia ter efeito sobre as instituições).

\section{Conclusão: reflexo ou proposição?}

Existem, portanto, maneiras diferentes de concluir um fórum deliberativo. Pode-se mostrar como as opiniões dos participantes mudaram; podem-se apresentar todos os discursos que circularam; pode-se concluir por uma de- 
claração compartilhada sob a forma de uma recomendação e, por fim, podese tomar uma decisão pelo voto. A escolha entre essas alternativas depende de vários fatores, sobretudo da natureza do tema em discussão. Há temas que demandam um aprofundamento dos problemas e das alternativas antes da decisão; em outros, decidir é possível e até mesmo desejável.

Contudo, deve-se salientar que a mesma questão pode ser tratada por meio de diferentes dispositivos, que preveem conclusões diferentes. Por exemplo, a decisão sobre a instalação de um equipamento indesejável (i.e., um incinerador) pode ser submetida a uma enquete deliberativa, que mostrará como os participantes modificam suas posições em um debate público, que levantará todos os argumentos e deixará a decisão ao responsável pelo projeto, ou a um júri de cidadãos, que emitirá pareceres ou tomará uma decisão mais ou menos coercitiva para as autoridades competentes. Em todos esses casos, haverá deliberação, mas com efeitos bem diferentes: seja sobre o desenrolar do processo, sobre o que se solicita aos participantes ou, sobretudo, sobre a escolha final. A relação entre o nível micro do fórum e o nível macro da sociedade ou do sistema de decisão será muito diferente.

A escolha do dispositivo (e de sua conclusão) tem uma importância crucial, pois a oferta de dispositivos passou a ser muito ampla e frequentemente acontece, na prática, de não haver muita reflexão sobre essa escolha.

A par da natureza da questão em jogo, existem vários argumentos favoráveis a uma conclusão firme ou propositiva. O primeiro deles é que ter de escolher incita os participantes a uma maior responsabilidade. Formulando novo parecer sobre uma boa deliberação, Jon Elster ressaltou que "o fórum deveria ter o direito de tomar uma decisão ou formular uma proposição que um outro grupo deveria aceitar ou rejeitar sem poder modificá-la" ${ }^{2}$ (sua referência é a assembleia sobre o sistema eleitoral

2 Comunicação na Biennale Democrazia, Turim, 23 de abril de 2009. 
na Colúmbia Britânica). Se uma verdadeira decisão não estiver em jogo, corre-se o risco de os participantes não levarem a sério seu papel e de a deliberação se reduzir a uma conversa leviana, gratuita, desengajada.

Poderíamos acrescentar, que uma deliberação só tem sentido se os participantes tiverem a possibilidade de resolver um problema, encontrar soluções, solucionar um conflito. A discussão não é importante apenas em si, mas por trazer uma contribuição coletiva a uma controvérsia. Sua conclusão natural é a superação de uma situação de bloqueio ou de incerteza.

$\mathrm{O}$ argumento mais frequentemente evocado pelas associações e pelos movimentos nos discursos sobre a "democracia participativa" para sustentar uma conclusão firme é o do empoderamento (empowerment), ou seja, dar aos cidadãos a possibilidade de contar. É evidente que a voz dos cidadãos só pode ser ouvida se for suficientemente clara, unívoca, decidida. A passagem do micro ao macro será mais efetiva se os participantes souberem se expressar claramente em uma única voz. É o argumento representado pela célebre escala de Arnstein (1969) - o texto mais citado na literatura sobre a participação -, que classifica os diferentes tipos de participação em relação ao poder que dão aos cidadãos. Para alcançar o topo da escala - o citizen power -, é preciso que os cidadãos sejam capazes de expressar-se de modo incontestável. As outras formas de conclusão, mais flexíveis, têm o inconveniente de delegar a decisão a outros grupos e, portanto, a deliberação corre o risco de ser um exercício inútil, que cria uma distância entre aqueles que "participam" e aqueles que "aproveitam", conforme o slogan de Maio de 1968², que Arnstein reproduz, e com razão, em seu artigo.

Todavia, existem também bons argumentos para desconfiar de conclusões claras e precisas demais. Simone Chambers (1999) observou que,

3 N. de T.: Je participe. Tu participes. II participe. Nous participons. Vous participez. Ils profitent [Eu participo, tu participas, ele participa. Vocês participam. Eles aproveitam]. 
quando uma decisão está em jogo, a deliberação corre o risco de perder em qualidade, porque os participantes tenderão a se fechar em suas posições e ficarão mais expostos às pressões do exterior ${ }^{4}$. De acordo com James Fishkin (1995, p. 185), os procedimentos que não requerem uma decisão do grupo evitam "a pressão social para chegar a um consenso". Recentemente, em uma cidadezinha da Toscana, a escolha sobre a localização de um pequeno equipamento para resíduos (um pirogaseificador) foi confiada a um júri de cidadãos sorteados entre os moradores próximos, que deviam primeiramente questionar o responsável pelo projeto e os especialistas e, depois, emitir um parecer (que era visto como coercitivo para a administração municipal) (ver quadro). Como havia uma grande oposição local ao equipamento, os jurados sofreram pressões fortes e contínuas durante os três meses de debate e, ao final, eles decidiram, por unanimidade, rejeitar a instalação do equipamento, mesmo que razões ambientais contra o incinerador se tenham revelado frágeis durante as audições. O que teria acontecido se o tema tivesse sido discutido - como teria sido possível - em um debate público (do tipo CNDP)? A discussão teria sido mais aprofundada? Os participantes teriam ficado mais livres? O projeto teria sido aceito?

4 Isso não se confirmou na experimentação mencionada de Setälä et al. (2010). 


\section{O pirogaseificador de Castelfranco (2010-2011)}

Uma empresa de tratamento de resíduos especiais, situada em Castelfranco, na Toscana, desejava ampliar suas atividades, instalando no mesmo local um pequeno equipamento tecnologicamente muito avançado (um pirogaseificador), e solicitou autorização ao município. Como lá havia uma oposição muito combativa (de moradores e ecologistas), o município e a empresa optaram por abrir um processo participativo sobre esse projeto e solicitaram à autoridade regional que o financiasse. A autoridade quis que todas as vozes pudessem se expressar. Assim, a administração do processo coube a um comitê de garantia formado por todas as partes envolvidas (autoridades públicas, associações, comitês de moradores); um júri de cinquenta cidadãos sorteados recebeu a tarefa de deliberar sobre o assunto. O comitê de garantia e o júri dos cidadãos mostraram-se muito desequilibrados em favor dos opositores. Após três meses de confrontos bastante duros, o júri emitiu um parecer muito negativo em relação ao equipamento, que o município aceitou, negando a autorização à empresa (Pillon e Romano, 2012). http://www.insiemeperdecidere.it/index.php

Aliás, uma conclusão do tipo "representação dos discursos" não é necessariamente isenta de efeitos. As evidências do debate púbico francês são, a esse respeito, ambivalentes, mas mostram que se chegou às vezes a resultados significativos. A influência de um argumento, de uma representação de um problema, de um relato, pode ser independente do poder que the é a priori confiado. Uma deliberação aprofundada, que esquadrinha os problemas, mostra novas possibilidades ou novas maneiras de ver as questões em jogo, pode ser mais eficaz do que uma deliberação pouco produtiva, mas com poder. O citizen power é um processo bem mais longo e complicado e com mais desvios do que Sherry Arnstein havia considerado (Tritter e McCallum, 2006; Collins e Ison, 2009).

E então: reflexo ou proposição? Não pretendo oferecer uma conclusão. Limitei-me a mostrar que o encerramento de um fórum deliberativo 
é um problema complexo e delicado. Como as experiências deliberativas estão se multiplicando, seria muito desejável que os teóricos e os profissionais implicados refletissem sobre esse assunto.

\section{Bibliografia}

ANDERSEN, Vibeke - HANSEN, Kasper. How deliberation makes better citizens: The Danish Deliberative Poll on the Euro. European Journal of Political Research. n. 46, p. 531-556, 2007.

ARNSTEIN, Sherry. A Ladder of Citizen Participation. Journal of the American Institute of Planner., n. 35, p. 216-224, 1969.

BOBBIO, Luigi - GIANNETTI, Daniela. Presentazione. Rivista Italiana di Politiche Pubbliche. n. 2, p. 5-14, 2007. [Numero monografico sulle giurie di cittadini]

BOBBIO, Luigi - RAVAZZI, Stefania. Cittadini comuni e decisioni pubbliche. L'esperienza di una giuria di cittadini. Studi organizzativi. n. 2, p. 89-112. 2006.

BOBBIO, Luigi. II dibattito pubblico sulle grandi opere. II caso dell'autostrada di Genova. Rivista italiana di politiche pubbliche. n. 1, p. 119-146, 2010.

BOBBIO, Luigi. Types of Deliberation. Journal of Public Deliberation. v.6, n. 2, 2010. Disponível em: < http://services.bepress.com/jpd/vol6/iss2/art1>.

BOY, Daniel, et al. Un exemple de démocratie participative. La 'conférence des citoyens' sur les organismes génétiquement modifiés. Revue française de science politique. n. 4-5, p. 779-809, 2000.

CARSON, Lynn. Improving Public Deliberative Practice: A Comparative Analysis of Two Italian Citizens' Jury Projects in 2006. Journal of Public Deliberation. v. 2, n. 1, 2006. Disponível em: < http://services.bepress.com/jpd/vol2/iss1/art12>.

CHAMBERS, Simone. Talking versus Voting: Legitimacy and Deliberative Democracy. Unpublished manuscript, University of Colorado, 1999.

COLLINS, Kevin - ISON, Ray. Jumping off Arnstein's Ladder: Social Learning as a New Policy Paradigm for Climate Change Adaptation, Environmental Policy and Governance, n. 19, p. 358-373, 2009.

CROSBY, Ned - NETHERCUT, Doug. Citizens Juries: Creating a Trustworthy Voice of the People. In: GASTIL John, LEVINE,Peter (Org.) The Deliberative Democracy Handbook: Strategies for Effective Civic Engagement in the Twenty-First Century. San Francisco: Jossey-Bass, 2005, p. 111-119. 
DRYZEK, John - NIEMEYER, Simon. Discursive Representation, American Political Science Review, v. 102, n. 4, p. 481-493, 2008.

FISHKIN, James. The Voice of the People: Public Opinion and Democracy, New Haven CT, Yale University Press, 1995.

FISHKIN, James. When the People Speak: Deliberative Democracy and Public Consultation. Oxford: Oxford University Press, 2009.

FLORIDIA, Antonio. Democrazia deliberativa e processi decisionali: la legge della Regione Toscana sulla partecipazione, Stato e mercato. n..82, p. 83-110, 2008.

FLORIDIA, Antonio. Democrazia deliberativa, strategie negoziali, strategie argomentative: un'analisi del Dibattito Pubblico sul caso Castelfalfi. Paper presented at the Sisp congress, Pavia v. 4, n.6, september 2008.

FOURNIAU, Jean-Michel. Information, Access to Decision-making and Public Debate in France: the Growing Demand for Deliberative Democracy. Science and Public Policy. v. 28, n. 6, p. 441-445, 2001.

FUNG, Archon. Survey article: Recipes for public spheres: Eight institutional design choices and their consequences. The Journal of Political Philosophy. n.11, p. 338-367, 2003.

GARRAMONE, Vito - AICARDI, Mario. Paradise I'Ost? Spunti per I'uso e I'analisi dell'Open Space Technology. Milano: F. Angeli, 2009

GARRAMONE, Vito - AICARDI, Mario. Democrazia partecipata ed Electronic Town Meeting: Incontri ravvicinati del terzo tipo. Milano: F. Angeli, 2011.

GOODIN, Robert. Innovation democracy: democratic theory and practice after the deliberative turn. Oxford: Oxford University Press, 2008.

HENDRIKS, Carolyn. Consensus Conferences and Planning Cells: Lay Citizen Deliberations. In: GASTIL, John, LEVINE, Peter (Org.) The Deliberative Democracy Handbook: Strategies for Effective Civic Engagement in the Twenty-First Century. San Francisco: Jossey-Bass, 2005, p. 80-110.

HENDRIKS, Carolyn. Integrated Deliberation: Reconciling civil society's dual role in deliberative democracy. Political Studies. n. 54, p. 486-508, 2006.

IRPET. Partecipazione, politiche pubbliche, territori: La L.R. 69/2007, 2011.Disponível em : < www.irpet.it>.

ISERNIA, Pierangelo et al. La democrazia in un ambiente ostile: un quasi-esperimento deliberativo. Stato e mercato. n. 3, p. 443-474, 2008.

JOSS, Simon. Danish consensus conferences as a model of participatory technology assessment: an impact study of consensus conferences on Danish Parliament and Danish publica debate. Science and Public Policy. v. 25, n. 1, p. 2-22, 1998. 
KADLEC, Alison. Critical Pragmatism and Deliberative Democracy. Theoria. p. 54-80, 2008.

LAURENT, Brice. Les politiques des nanotechnologies. Pour un traitement démocratique d'une science émergente. Paris: Charles Léopold Mayer, 2010.

LUKENSMEYER, Carolyn et al. A Town Meeting for the Twenty-First Century. In: GASTIL, John, LEVINE, Peter (Org.) The Deliberative Democracy Handbook: Strategies for Effective Civic Engagement in the Twenty-First Century. San Francisco: Jossey-Bass, 2005, p. 154-163.

MANIN, Bernard. Déliberation et discussion. Revue Suisse de Science Politique. v.10, n. 4, p. 180-192, 2005.

MANSBRIDGE, Jane. et al. A Systemic Approach to Deliberative Democracy, Paper presented at ECPR Joint Session, St Gallen, v.12, n.16, April 2011.

NIEMEYER, Simon - DRYZEK John. The Ends of Deliberation: Meta-consensus and Inter-subjective Rationality as Ideal Outcomes. Swiss Political Science Review. v. 13, n. 4, p. 497-526, 2007.

OWEN, Harrison. Open Space Technology: User's Guide. San Francisco: BarrettKoehler, 1997.

PILLON, Andrea - ROMANO, Iolanda. Percorso partecipativo su un conflitto: il caso del pirogassificatore di Castelfranco di Sotto. In: PERRONE, Camilla (Org.), A che serve partecipare? Firenze: Firenze University Press, 2012.

POMATTO, Gianfranco. Gioco strategico e deliberazione: il dibattito pubblico sulla gronda di Genova. Torino: Dps University Press, 2011.

RAVAZZI, Stefania. Gli esiti di un Electronic Town Meeting. In: GARRAMONE, Vito - AICARDI, Marco (Org.), Democrazia partecipata ed Electronic Town Meeting. Incontri ravvicinati del terzo tipo. Milano: F. Angeli, 2011, p. 119-133.

REVEL, Martine et al. Le débat public: une expérience française de démocratie participative. Paris: La Découverte, 2007.

SETÄLÄ, Maija et al. Citizen Deliberation on Nuclear Power: A Comparison of Two Decision-Making Methods. Political Studies. n. 58, p. 688-714, 2010.

SUNSTEIN, Cass R. The Law of Group Polarization. Journal of Political Philosophy. v.10, n. 2, p. 175-195, 2002.

TRITTER, Jonathan Q., MCCALLUM, Alison. The snakes and ladders of user involvement: Moving beyond Arnstein. Health Policy. n.76, p. 156-168, 2006

URFALINO, Philippe. La délibération n'est pas une conversation, Délibération, décision collective et négociation. Négociations. n.2, p. 99-114, 2005. 
WARREN, Mark - PEARSE, Hilary. (Org.). Designing Deliberative Democracy: The British Columbia Citizens' Assembly. Cambridge: Cambridge University Press, 2008.

YOUNG, Iris. Activist challenges to deliberative democracy. Political Theory. v.29, n. 5, p. 670-690, 2001.

Recebido em: 05/12/2011

Aceite final: 28/02/2012 